\title{
The Shared Cataloging Program; the Importance of Being Ordered
}

\begin{abstract}
The Shared Cataloging Program at the Library of Congress attempts to assign top priority to the cataloging of items for which copy has been requested by research libraries. Regrettably the process is slowed considerably by the large number of inaccurate and unrevised citations submitted by participating libraries. Care should be taken in research libraries to assure that only accurate references are given, that national bibliography number is included, that the requesting institution is identified, and that orders are typed. Examples of bad citations are given.
\end{abstract}

B Y ACCORDING TOP priority to each university order for a current foreign title, from the ordering through the printing process, the Library of Congress is expending considerable effort to provide research libraries with the cataloging copy they need at the earliest possible moment.

It has been less generally recognized that research libraries have a corresponding responsibility for the efficient functioning of the Title II program; that is, the bibliographical screening of all orders forwarded to the Library of Congress.

Thus far no coherent policy for the submission of these orders seems to have been devised, and any and every order that might conceivably come within the province of the Shared Cataloging Division is being submitted, regardless of whether the Library of Congress had undertaken to catalog such material or not. Moreover, many submissions have totally inadequate bibliographical identification. This creates unnecessary work

Miss Williams is Assistant Acquisitions Librarian in the Cornell University Library. and threatens to impede the speed and efficiency of the program. The following strictures therefore represent an attempt to point out a policy for the screening of foreign orders forwarded to the $\mathrm{Li}$ brary of Congress for cataloging priority.

Ideally all such orders should be screened by acquisitions librarians with cataloging experience if duplication and incorrent searching are to be avoided and orders correctly controlled. Each order forwarded to the Library of Congress must, of necessity, be accepted there at face value, and, if not in stock, ordered; therefore an incorrect order can result in a costly and time-consuming duplicate. As a recent article in $\mathrm{Li}$ brary Resources \& Technical Services ${ }^{1}$ points out, however, the growth of new schools and increasing book budgets have resulted in many librarians being assigned to acquisitions work with inadequate training and job experience.

The most important and desirable element in an order submitted for cataloging priority is the national bibliography

${ }^{1}$ A. Dahl-Hansen and R. M. Dougherty, "Acquisitions in 1967," Library Resources \& Technical Seroices, XII (Spring 1968), 182. 
number, e.g., Au 66-14-192, GDB 66A29-67, GDNB 66-A42-117, B 67-8637, Sw 66-A22-4645, Ne 67-5. This entails more initial searching than is usually provided presently, but it is a vital identification in the event of any query, and in so comprehensive a collection queries occur with unfortunate frequency. This bibliographical identification enables the searcher to pinpoint and order exactly what is needed from the plethora of available variations; such exact identification ensures speedier cataloging.

It would seem to be stating the obvious to say that all requests should be identified with the name of the submitting library (this also applies to all orders to the Card Division), but many arrive anonymously. It would also seem superfluous to ask that all entries be typewritten; it is surprising how many handwritten orders arrive, the best of which are open to misinterpretation. In the vast files of the Library of Congress, an error of only one letter can often cause the irretrievable burial of the desired citation, despite sheer genius on the part of the searching staff. For this reason such variants as umlauts should always be spelled out in full. Carbon copies must be legible; many unfortunately are not. Ideally a standard form should be used for all orders submitted, but this is at best a future development.

For the present, serials are specifically excluded from the Shared Cataloging Program; likewise series are omitted, although individual titles are accepted. It is therefore a waste of time and money to submit orders for such items.

There must be no ambiguity as to the author, as far as he is ascertainable at the time of ordering. It is awkward and time-consuming for the searcher to be confronted with "erzaehlt von Eugen Heberle" as the author; and certainly "Author: Roth, Eugen, introduction by" and "Title: Panorama Buecher" leave something to be desired. Similarly, a series should not be quoted as the author.
The following entry, with its duplicate-causing potential, should not have been submitted to the Library of Congress in this fashion, and yet it was submitted: "Author: Luck, George, 1926- , ed. Title: Ovid. Tristia."

Correct bibliographical identification, the result of intensive searching, is essential. At first sight "Author: PaulyWissowa, August Friedrich von. Title: Der kleine Pauly," would seem satisfactory, yet careful searching would have revealed that this is cataloged under title, and a $\$ 26.00$ duplicate would have been saved.

Genius, and a superb knowledge of the resources, unravelled the mystery of "Author: Halbkuegel, Nordliche. Title: Prakaembrium."

Cataloging scrutiny would have realized the possibility of error in an order submitted as "Author: Weber, Max. Title: Gedaechtnisschrift der Ludwig-Maximilians Universitaet Muenster zur 100. Wiederkehr seines Geburtstages. Hrsg. von Karl Engisch, Bernard Pfister, Johannes Winckelmann."

Scrutiny would also ensure more accurate detail; for example, "Ganzleinen" is unlikely to be the place of publication.

The classic example of a totally incomprehensible order is "Title: Form $36-P \$$ Koeln, Westdeutscher Verlag Redaktion." This was returned to the offender with a large red question mark.

As a general rule it seems pointless to submit reprint editions for cataloging priority, when the original has already been cataloged by the Library of Congress; this principle could be applied to the subsequent editions of many works and reduce, to a substantial extent, the sheer volume of orders handled.

The current flood of unrevised orders slows down the operational speed of the Shared Cataloging Program, and intensive screening could reduce this to somewhat more manageable proportions. 